\title{
Upaya Peningkatan Pengetahuan tentang Penyakit Jantung Koroner pada Lansia di Posyandu Lansia Kelurahan Rawasari
}

\author{
Marta Suri \\ Program Studi S1 Keperawatan, STIKes Baiturrahim Jambi \\ email:martasuri85@gmail.com
}

Submitted : 27/12/2020

Accepted: 19/10/2021

Published: 19/11/2021

\begin{abstract}
Coronary heart disease is caused by various factors that can cause an increase in the incidence / deposits of cholesterol which narrow the vessels in the whole body including the coronary vessels. Coronary heart disease has become the leading cause of death in Indonesia. According to WHO in 2005, the number of deaths from cardiovascular disease (especially coronary heart disease, stroke, and rheumatic heart disease) increased globally to 17.5 million from 14.4 million in 1990. The results of the situation have been obtained from RT 12 KelurahanRawasariKecamatanAlamBarajo, Jambi City, in this sub-districthealth services such as Intregated Service Post (Posyandu) have been established. However, there is no scheduled health education as a promotive and preventive effort to overcome the problem of the high incidence of people experiencing heart disease. The results of health education activities for the elderly are expected to understand the concept of nursing problems that cause coronary heart disease.
\end{abstract}

Keywords: elderly, coronary heart disease, knowledge enhancement

\begin{abstract}
Abstrak
PenyakitJantungKoroner disebabkan oleh berbagai faktor yang dapat menyebabkan peningkatan timbulnya/deposit kolestrol yang mempersempit pembuluh diselutuh tubuh termasuk pembuluh koroner.Penyakit jantung koroner telah menjadi penyebab kematian utama di Indonesia. Menurut WHO tahun 2005, jumlah kematian penyakit kardiovaskular (terutama penyakit jantung koroner, stroke, dan penyakit jantung rematik) meningkat secara global menjadi 17,5 juta dari 14,4 juta pada tahun 1990. Hasil situasi yang telah didapatkan dari RT 12 Kelurahan Rawasari Kecamatan Alam Barajo Kota Jambi, pada Kelurahan tersebut sudah terbentuk layanan kesehatan seperti posyandu. Namun, belum adanya pendidikan kesehatan yang terjadwal sebagai upaya promotif dan preventif untuk menanggulangi masalah tingginya angka kejadian masyarakat yang mengalami penyakit jantung.Hasil dari kegiatan penyuluhan kesehatan pada lansia diharapkan lansia memahami konsep tentang masalah keperawatan penyebab penyakit jantung koroner.
\end{abstract}

Kata Kunci :lanjut usia, peningkatan pengetahuan, penyakit jantung koroner

\section{PENDAHULUAN}

Seiring dengan semakin meningkatnya populasi lanjut usia, pemerintah telah merumuskan berbagai kebijakan pelayanan kesehatan lanjut usia ditujukan untuk meningkatkan derajat kesehatan dan mutu kesehatan lanjut usia untuk mencapai masa tua bahagia dan berguna dalam kehidupan keluarga dan masyarakat sesuai dengan keberadaannya. Sebagai wujud nyata pelayanan sosial dan kesehatan pada lanjut usia, pemerintah telah mencanangkan pelayanan pada lanjut usia melalui beberapa jenjang. Pelayanan ditingkat masyarakat adalah Posyandu Lansia, pelayanan kesehatan lansia tingkat dasar adalah Puskesmas, dan pelayanan kesehatan tingkat lanjutan adalah Rumah Sakit (Fallen, 2011).

Jumlah penduduk lanjut usia menunjukkan peningkatan dari tahun ke tahun. Hal yang sejalan dengan meningkatnya usia harapan hidup serta menjadi tanda membaiknya tingkatkesejahteraan masyarakat. Hasil Sensus Penduduk tahun 2010 menunjukkan 
bahwa Indonesia termasuk lima besar negara dengan jumlah penduduk lanjut usia terbanyak di dunia yaitu mencapai 18,1 juta jiwa pada 2010 atau 9,6 persen dari jumlah penduduk (Abdi, 2013). Tahun 2014 jumlah lansia meningkat mencapai 18,8 juta jiwa, sedangkan tahun 2020 diprediksi 28,8 juta jiwa atau $11.34 \%$ dari total jumlah penduduk.

Seiring pertambahan usia, maka terjadi penyakit degeneratif antara lain penyakit jantung koroner. Kasus dengan penyakit jantung koroner salah satu jenis kasus yang umunya diderita oleh kalangan siapa saja, khususnya penyakit ini meningkat pada kalangan orang tua (lansia). Disebabkan oleh berbagai faktor yang dapat menyebabkan peningkatan timbulnya/deposit kolestrol yang mempersempit pembuluh diselutuh tubuh termasuk pembluh koroner. Faktor-faktor tersebut antara lai: Asap rokok, hipertensi, kadar kolestrol dan trigliserida darah yang tinggi, aktivitas fisik yang kurang adekuat, obesitas, diabetes, alkohol, riwayat penyakit antung dalam keluarga dan jenis kelamin.

Penyakit jantung koroner telah menjadi penyebab kematian utama di Indonesia. Menurut WHO tahun 2005, jumlah kematian penyakit kardiovaskular (terutama penyakit jantung koroner, stroke, dan penyakit jantung rematik) meningkat secara global menjadi 17,5 juta dari 14,4 juta pada tahun 1990. Berdasarkan jumlah tersebut, 7,6 juta dikaitkan dengan penyakit jantung koroner. American Heart Association (AHA) pada tahun 2004 memperkirakan prevalensi penyakit jantung koroner di Amerika Serikat sekitar 13.200.000.3,4 Hasil Riskesdas tahun 2007 menunjukkan PJK menempati peringkat ke3 penyebab kematian setelah stroke dan hipertensi. Angka kejadian penyakit jantung koroner berdasarkan data Riset kesehatan dasar (Riskesdas) Kementerian Kesehatan 2007, ada sebanyak 7,2\%. Di Provinsi Jawa Tengah berdasarkan laporan dari rumah sakit dan puskesmas tahun 2006, kasus
Penyakit Jantung Koroner sebesar 26,38 per 1.000 penduduk. Meski menjadi pembunuh utama, tetapi masih sedikit sekali orang yang tahu tentang PJK dan faktor risikonya. Dalam ilmu epidemiologi, jika faktor risiko suatu penyakit telah diketahui maka akan lebih mudah untuk melakukan tindakan pencegahan. Karena bagaimanapun mencegah lebih baik dari pada mengobati. 5,6,7 Penderita PJK banyak didapatkan adanya faktor - faktor risiko.

Faktor risiko utama atau fundamental yaitu faktor risiko lipida yang meliputi kadar kolesterol dan trigliserida, karena pentingnya sifat - sifat substansi ini dalam mendorong timbulnya plak di arteri koroner.Negara Amerika pada saat ini 50\% orang dewasa didapatkan kadar kolesterolnya $>200 \mathrm{mg} / \mathrm{dl}$ dan $\pm 25 \%$ dari orang dewasa umur $>20$ tahun dengan kadar kolesterol > $240 \mathrm{mg} / \mathrm{dl}$, sehingga risiko terhadap penyakit jantung koroner akan meningkat. Penderita penyakit jantung koroner akan mengalami hipertensi 2,25 kali dibanding dengan yang bukan penderita penyakit jantung koroner.Berbagai penelitian epidemiologi menunjukkan adanya keadaan-keadaan sifat dan kelainan yang dapat mempercepat terjadinya penyakit jantung koroner. Memiliki faktor risiko lebih dari satu seperti hipertensi, diabetes melitus, dan obesitas, maka akan mempunyai 2 atau 3 kali berpeluang terkena penyakit jantung koroner dibandingkan 70 orang yang tidak.

Berdasarkan Undang-Undang no 36 tahun 2009 pemerintah wajib menjaga kesehatan masyarakat lanjut usia agar tetap hidup sehat dan produktif secara sosial dan ekonomi. Untuk itu perlu diselenggarakannya upaya kesehatan dengan pendekatan promtif, preventif, kuratif dan rehabilitatif yang dilaksanakan secara menyeluruh, terpadu dan berkesinambungan. Upaya kesehatan masyarakat adalah setiap kegiatan yang dilakukan oleh pemerintah, swasta, masyarakat dalam upaya memelihara dan 
meningkatkan kesehatan serta mencegah dan menanggulangi timbulnya masalah kesehatan di masyarakat. Salah satu upaya tersebut adalah upaya peningkatan kesehatan pada lansia.

Upaya kesehatan pada lansia, dimulai dengn deteksi dini terhadap penykit, penceghan penyakit, perawatan bila sakit dan upaya terjdinya penceghan komplikasi. Banyak lansia yang menderita penyakit jantung koroner dan tidak mengetahui penyebab dari penyakit jantung koroner dan tidak mengetahui makanan atau apa saja yang harus dihindari untuk dikonsumsi. Oleh karena itu perlu dilakukan peningkatan pengetahuan pada lansia tentang penyakit jantung koroner. Pendidikan kesehatan ini dilakukan untuk memberikan edukasi ke masyarakat khususnya lansia agar lansia lebih mengerti dan memahami apa itu penyakit jantung koroner serta apa yang harus dihindari dan pencegahannya. Setelah mendapatkan pendidikan kesehatan, lansia dapat memperkenalkan (mempromosikan) pentingnya kesehatan pada keluarga di rumah, sihingga secara tidak langsung dapat meningkatkan derajat kesehatan masyarakat.

Hasil situasi yang telah didapatkan dari RT 12 Kelurahan Rawasari Kecamatan Alam Barajo Kota Jambi, pada Kelurahan tersebut sudah terbentuk layanan kesehatan seperti posyandu. Namun, belum adanya pendidikan kesehatan yang terjadwal sebagai upaya promotif dan preventif untuk menanggulangi masalah tingginya angka kejadian masyarakat yang mengalami penyakit jantung.

Pemberian pendidikan kesehatan tentang penyakit jantung koroner pada masyarakat sangat tepat dalam rangka upaya promotif dan preventif untuk menekankan angka kejadian penyakit jantuung koroner. Pendidikan kesehatan diharapkan mampu memberikan pengetahuan kepada lansia akan pentingnya menjaga kesehatan tubuh.
Dari permasalahan mitra tersebut dapat diketahui, pos yandu lansia dibawah wilayah kerja puskesmas rawasari telah melaksanakan kegiatan posyandu lansia sesuai dengan tugas posyandu bagi masyarakat. Namun, pelaksanaan berbagai kegiatan tersebut belum optimal dan masih memiliki keterbatasan maupun lansia itu sendiri. Oleh karena itu kami tim engabdian kepada masyarakat ini merasa peru melakukan upaya promotif dan preventif melalui kegiatan pendidikan kesehatan kepada lansia.

\section{TARGET DAN LUARAN}

Target dari kegiatan pengabdian ini adalah lansia di RT 12 Kelurahan Rawasari Kecamatan Alam Barajo. Luaranya adalah meningkatkan pengetahuan lansia tentang penyakit jantung koroner, pengertian, tanda dan gejala, penyabab, komplikasi, perawatan dan pencegahan terjadinya penyakit jantung koroner.

\section{METODE PELAKSANAAN}

Kegiatan pengadian masyarakat ini dilakukan pada bulan Nopember 2019Januari 2020 di Posyandu Lansia RT 12 kelurahan Alam Barajo kota Jambi, Metode pelaksanaan yang digunakan adalah survey, observasi, waancara, ceramaah, tanya jawab, demonstrasi terkait ramuan tradisional untuk mengatasi penyakit jantung koroner pada lansia yang diikuti oleh 20 lansia, laki-laki dan perempuan. Selain mitra dan pelaksanaan kegiatan ini dibantu oleh beberapa orang mahasiswa Program S1 Keperawatan STIKes Baiturrahim Jambi.

\section{HASIL DAN PEMBAHASAN}

Hasil kegiatan pengambilan kepada masyarakat yang telah dilaksanakan dengan mitra Posyandu Lansia RT 12 kelurahan Rawasari Kecamatan Alam Barajo adalah sebagi berikut : 
1. Hasil servey, observasi dan wawancara menunjukan bahwa sebagian besar lansia belum mengetahui tentang penyakit jantung koroner.

2. Hasil pemriksaan asam urat, $15 \%$ dari lansia yang hadir menderita penyakit jantung koroner.

3. Sebelum diberikan pendidian kesehatan, sebagian bsar lansia mengatakan masih belum mengetahui tentang pengertian penyakit jantung koroner, penyebab, tanda dan gejala, perawatan, makanan yang perlu dikonsumsi dan dihindari, pencegahan penyakit jantung koroner serta terapi komplementer dengan ramuan tadisional untuk penyakit jantung koroner. Namun, setelah diberikan pendidikan kesehatan sebagianbesar lansia mulai memahami dan aktif betanya serta mengungkapkan masalah kesehatan khususnya penyakit jantung koroner yang diderita oleh lansia.

4. Sebagian besar lansia menunjukan sikap positif terhadap pelaksanaan kegiatan pendidikan kesehatan dengan mengikuti dari awal sampai selesai kegiatan pendidikan kesehatan ini.

Pendidikan kesehatan membawa perbahan perilaku pada individu, kelompok dan populasi yang lebih besar dari prilaku yang dianggap merugikan kesehatan, prilaku yang kondusif untuk kesehatan masa kini dan masa depan, (simond,1976). Perhatian utama dan tujuan dari pendidikan kesehatan adalah prilaku kesehatan. Prilaku kesehatan adalah respon seseorang terhadap stimulus atau objek yang berkaitan dengan sakit dan penyakit, sistem pelayanan kesehatan, makanan dan minuman serta lingkungan. Prilaku kesehatan terdiri dari tiga domain yaitu pengetahuan, sikap dan tindakan (Notoadmojo,2010). Menurut teori L.Gren dalam Notoadmojo (2012) terdapat tiga faktor yang mempengaruhi prilaku seseorang yaitu 1) predisposing factors berupa pengetahuan, sikap, kepercayaan, nilai-nilai dan persepsi; 2) enabling factors berupa keterampilan, ketersedian sumber daya seperti sarana dan prasarana kesehatan seperti rumah sakit, puskesmas, obatobatan, tenaga kesehatan serta keterjangkauan sumber-sumber tersebut oleh individu atau masyaakat; 3) renforcing factors melputi sikap dan prilaku tenaga kesehatan atau petugas lainnya, orang tua, tokoh masyarakat, kelompok terentu, dan lainya yang menjadi panutan bagi individu atau masyarakat untuk berprilaku.

Perilaku kesehatan berkaitan dengan sifat afektif, emosioal dan pola perilaku, tindakan dan kebiasaan yang berkaitan dengan pemeliharaan kesehatan, pemulihan kesehatan dan perbaikan kesehatan (Gochman, 1982-1997). Dalam hal ini, pengetahuan lansia tentang penyakit jantung koroner dan berbagai hal yang terkait dengan penyakit jantung koroner akan mempengaruhi sikap dan tindakan yang akan dilakukan oleh lansia. Kurangnya pengetahuan lansia tentang penyakit jantung koroner diduga karena berdampak pada prilaku lansia terkait dengan pola hidup sehat, misalnya pemilihan makanan yang boleh dan tidak boleh dikonsusmsi untuk penderita penyakit jantung koroner serta keinginan untuk memeriksakan kesehatan. Kurangnya pengetahuan lansia tentang penyakit jantung koroner diduga berdampak pada prilaku lansia terkait pola hidup sehat. Misalnya pemilihan makanan yang boleh atau tidak boleh untuk pendeita penyakit jantung koroner serta keinginan untuk memeriksakan kesehatannya. Kurangnya pengetahuan tersebut berhubungan dengan tngkat pendidikan lansia atau keterpaparan informasi pada lansia terkait dengan penyakit jantung koroner.

Pelaksanaan kegiatan pendidkan kesehatan kepada lansia pada kegiatan pengabdian ini dapat dilihat pada beberapa dokumentasi berikut : 

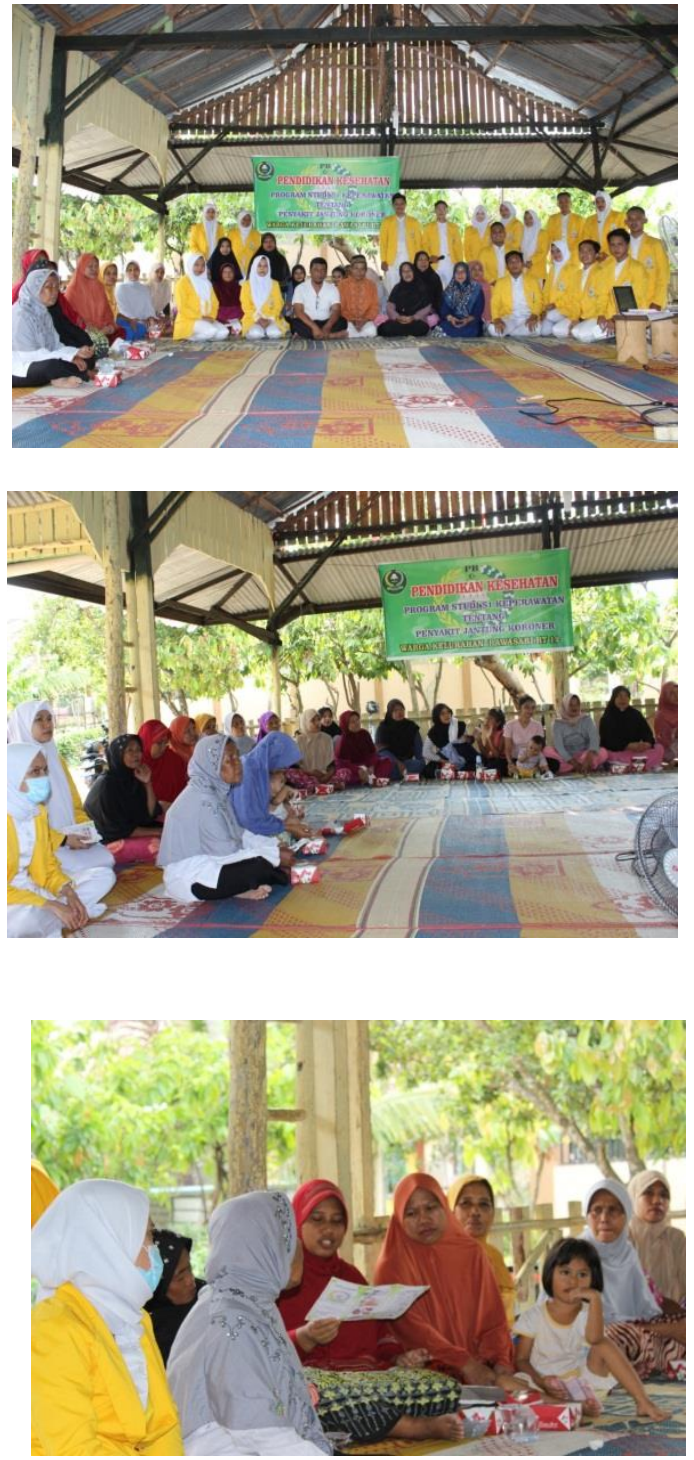

Gambar. 1,2 dan 3

Kegiatan Edukasi oleh Tim Pengabdian Masyarakat

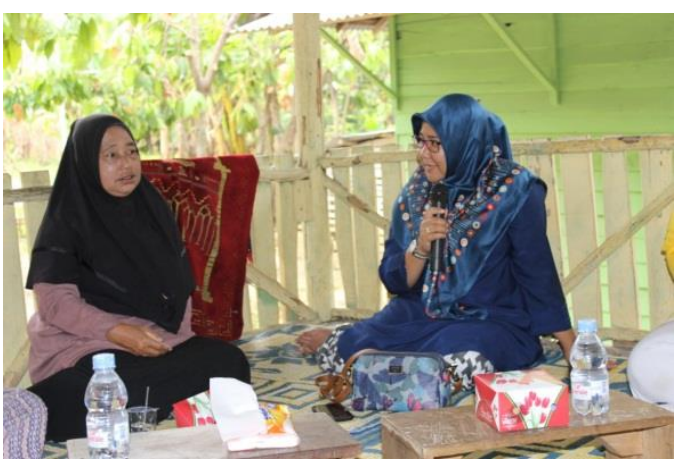

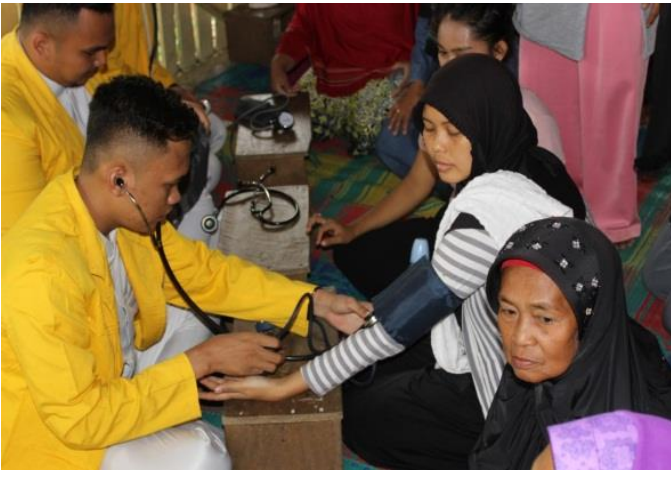

Gambar, 4 dan 5

Pelaksanaan Pemeriksaan Tekanan Darah

\section{KESIMPULAN DAN SARAN}

\section{Kesimpulan}

Secara umum, Posyandu lansia RT 12 Kelurahan Rawasari Kec. Alam Barajo telah melakukan kegiatan posyandu sesuai program, namun pada pelaksanaanya, perlu dukungan kerjasama dari institusi kesehatan untuk mengoptimalkan pelaksanaan program pendidikan kesehatan dan pemeriksaan kesehatan secara terjadwal dengan materi pendidikan kesehatan yang beragam, sehingga lansia memiliki pengetahuan atau persepsi yang sama terhadap penyakit degeneratif khususnya penyakit jantung koroner.

\section{Saran}

Disarankan kepada petugas kesehatan, khususnya kepada unit kesehatan lansia dan kader posyandu lansia untik dapat meningkatkan program pada posyandu lansia, sehinga tercapai tujuan pemerintah yaitu peningkatan kesehatan lansia untuk tetap hidup sehat dan produktif secara sosial dan ekonomi sesuai dengan UU no 36 tahun 2009.

\section{UCAPAN TERIMA KASIH}

Semua tim dan mitra pada kegiatan pengabdian ini menguvapkan terima kasih kepada:

1. Kepada Dinas Ksehatan Kota Jambi beserta jajaranya.

2. Kepada UPTD Puskesmas Rawa Sari Jambi beserta jajaranya. 
3. Mitra dan Puskesmas Rawasari Yaitu Posyandu Lansia RT 12 Kelurahan Rawasari Kecamatan Alam Barajo.

4. Ketua STIKes Baiturrahim Jambi beserta jajarannya.

5. Semua pihak yang membantu terlaksananya kegitan ini.

\section{DAFTAR PUSTAKA}

Gray,H. H. Et al. 2015. Lecture Noes : kardiologi. Jakarta: Erlangga

Joewono.B.S.2007. Ilmu Penyakit Jantung, Suabaya, Airlangga University Press

Notoatmodjo, S. 2010. Promosi kesehatan dan ilmu perilaku. Jakarta: Rineka Cipta

Sarwono.2015. Buku Ajar : Ilmu Penyakit Dalam. Jilid I: Edisi 3. Jakarta.FKUI

Suddarth \& Brunner. 2007. Keperawatan Medikal Beah: Edisi 8. Jakarta.EGC 